\title{
Modelling production ramp-up of engineering products
}

\section{P D Ball, S Roberts, A Natalicchio and C Scorzafave}

Department of Manufacturing, Cranfield University, Cranfield, UK

The manuscript was submitted on 15 March 2010 to Proceedings of the IMechE Part B Journal of Engineering Manufacture and revised on 9 July 2010 with final revision on 11 August 2010.

\begin{abstract}
Companies that introduce new products quickly have been shown to be better performers. The effectiveness of the new product introduction process is critical to their performance. Production ramp-up is a necessary phase of new product introduction and both planning and execution need careful consideration especially for engineered products which are generally typified by design, purchasing and production complexity. Better understanding of the issues and more effective modelling of options should lead to more predictable and quicker ramp-up. Examination of the literature, however, reveals little attention has been paid to this area. What knowledge exists tends to concentrate on specific aspects such as capacity or learning or costs. This paper reviews the ramp-up literature in general along with the specific components in more detail to establish how current work can be combined to develop the architecture for a modelling tool for engineering product ramp-up. The contribution of the paper is to provide a wider view of ramp-up, to present it as a topic worthy of consideration in its own right, and to introduce a prototype modelling tool which can aid the investigation and solutions of the issues that the paper raises.
\end{abstract}

Keywords: production ramp-up modelling, learning curves, new product introduction, engineering products

\section{INTRODUCTION}

Demanding customer expectations makes competitiveness a vital issue for any industry. In the engineering products sector in particular, the high level of initial investment needed for the introduction of a new product strengthens the requirement for effective production planning to efficiently utilise resources and avoid waste. If managed well, it can bring important competitive advantages to companies.

Ramp-up has a notable importance for companies because time-to-volume directly affects the financial success of a product [1]. In particular, time-to-volume has a significant effect on the net present value and revenues of a project. If the time-to-volume is delayed respect to the forecast, revenues will be postponed; hence a shorter ramp-up reduces the payback period and improves financial indicators, such as return on investment and return on assets compared to a longer one [2]. In addition, market share and revenue can be lost if delivery to customer is delayed due to ineffective ramp-up. This is even more apparent in competitive markets [3].

\footnotetext{
Corresponding author: Department of Manufacturing (B50), Cranfield University, Cranfield, Bedfordshire MK43 OAL, UK. email: p.d.ball@cranfield.ac.uk
} 
Effective cost analysis is vital in this context to fully understand the feasibility of a new product and the effort needed. Considering the magnitude of the investment for the rampup of an engineering product and the importance of the learning phenomenon in the production process, any planning inaccuracy might have heavy consequences on the company finances. Having good information can play a crucial role at the early stages of the production planning and decision making process.

The introduction of new products onto the shop floor needs to be carefully assessed in order to manage them effectively and efficiently. Learning effects are commonly registered during ramp-up. The literature shows some examples of industries for which the ramp-up has been studied due to its importance. Principally, examples include electronics industry [4], automotive [5] and aerospace [6]. In spite of this, the literature does not provide the depth of information relative to the importance of the topic. Learning curves are extensively explored in the literature as are cost analysis and capacity analysis. However, there is a gap in the literature when considering these areas together for the ramp-up of new products, especially engineering products where complexity is high.

This paper therefore examines the technical and economic perspectives of ramp-up and uses these to develop an architecture for modelling. In turn a prototype modelling tool is developed and tested. The contribution is therefore a broader view of ramp-up through the integration of learning, capacity and cost into a modelling approach.

\section{CONTEXT}

The production of a new item generally shows a ramp-up period during which the productivity and the output rate increase until reaching steady state (serial production) [7]. The exact definition in the literature is less clear. Authors differ in the definitions they provide:

- "ramp-up is a technical concept and is the period preceding the market production launch" [8]

- ramp-up includes the pre-production and the production stages [9]

- ramp-up is the "period between completion of development and the full capacity utilisation" [4]

- the time from the production of the first item to reach steady-state output rate [3]

- the time interval from the end of the prototyping phase to the full volume production [10]

- ramp-up is the "initial period of commercial production [...] it begins at start of production and finishes when initial targets for, e.g. quality, volume, yield and costs are reached" [11]

Authors agree on the steep increase of output rate reported during this phase, but they disagree about the chronological limits of the process. Moreover, sometimes terms such as ramp-up and start-up are used interchangeably (start-up is the whole phase of output rate increase; ramp-up is only the phase during which a steep rise of the output rate is verified [5], see Figure 1). Indeed, sometimes the earlier part of the start-up is so short that the two terms coincide. In some cases synonyms are used to indicate the ramp-up concept. Pruett and Thomas [12] for example refer to the 'innovation process' as a set of activities that occur during the product development stage and before regular production begins. Within this work the commercial launching and marketing side discussed by Lenfle and Midler [8] will be excluded. 


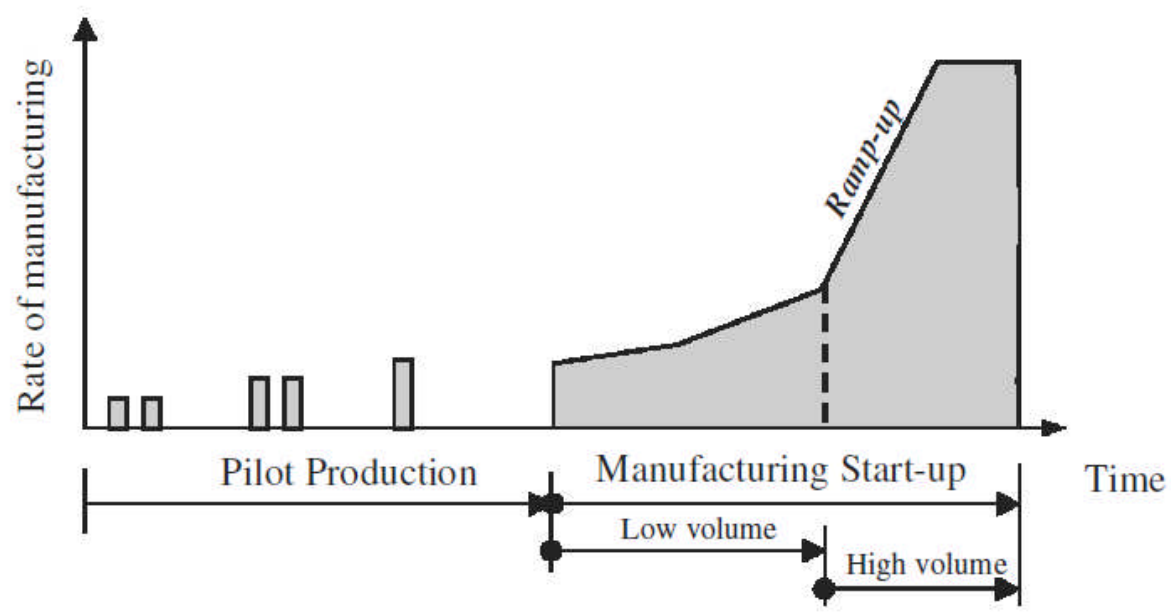

Figure 1. Distinction between start-up and ramp-up [5]

The definition used in this paper is close to the one given by Fjallstrom et al. [11] but is more tightly defined by Agaga et al. [13]: Ramp-up is "a process, normally within a manufacturing environment, where production moves from low rate and gradually increases to the required production rate as the manufacturing processes are proven".

It is generally assumed that production systems not in ramp-up are in steady-state for which there is a significant body of knowledge. Extensive work exists on designing new production systems, implementing them and then controlling and improving them. Relatively, there is little literature available on non-steady-state production systems, including ramp-up, despite a growing acceptance of shrinking product life cycles and having production systems that are responsive to customer requirements.

In spite of the number of sources quoted, finding literature on production ramp-up is challenging. A commonly accepted body of knowledge is still missing. What does exist tends to be concentrated in large companies [14] and suggests high volume such as that experienced in the automotive industry. This is in contrast to the wealth of knowledge of designing for and improving systems in steady state. Additionally, there is little available evidence of well documented practice in industry. Within the case company examined later, whilst there was a depth of experience of previous product ramp-ups there was an absence of well defined processes with supporting tools. The challenge was how their decision making process surrounding ramp-up could be improved. Comparing the importance of effective ramp-up of new products with the relative unavailability of information, the contribution of this work is to provide a broad approach to practical production ramp-up.

\section{AIM AND APPROACH}

The wider aim of this work is to create a framework by which production ramp-up of engineering products can be modelled. In turn the modelling approach can be used to assess the impacts of changes to the production system configuration and policies. Significant variables affecting the ramp-up of engineered products are layout space, tooling availability, process capability, operator skill and learning rate as well as resulting recurring costs and non-recurring costs. The work was triggered by industrial need. The motivation for pursuing this research was the lack of comprehensive coverage of ramp-up 
in the literature, the lack of literature on the integration of the above mentioned variables and an absence of modelling tools.

The research question was "How can modelling of capacity, learning and costs of production ramp up be integrated?" The lack of available software and the disparate nature of the literature necessitated an exploratory case-based approach. Meredith's theory creation cycle [15] of description, explanation and testing of was used. The cycle is iterative with just over one complete cycle to enable useful outcomes to be extracted.

In the descriptive phase, the research issue was identified and as a result of exploratory analysis the above research question was established and the research design initiated. The explanation phase of the research would start with a literature review of ramp-up, new product introduction, learning and costs using well established databases. It was likely that the search would use an evolving collection of key words evident later. Analysis of the outcomes of literature review would enable the creation of a conceptual model (later referred to as model architecture). Moving into the testing phase of the research, component mechanisms would be developed using software and brought together in a final software form based on the requirements and data from an industrial case. Experimentation using the software would feed into the next descriptive phase through testing both the value of the modelling approach as well as provide benefit to the case company, thereby showing contributions to both theory as well as practice. Given the start point, alternatives of starting with hypotheses would be difficulty due to lack of integrated theory and using tools such as survey would be challenging due to the lack of common and documented methods across industry.

In the execution of this methodology, it was clear early on significant literature for particular subject areas exists, however, there was a challenge in sourcing articles that combined the areas. Next concepts and mechanisms were combined to create a modelling tool architecture with a breadth that is absent from the literature. A case company was used to test the architecture through the creation of a prototype modelling tool implemented as a comprehensive spreadsheet. It was not the intention to create a generic modelling tool at this stage. The data for the case specific engineering product manufacturer was entered and verified. Finally, experimentation was carried out for different ramp-up scenarios to understand the specific relationships between process configuration, learning and costs for different ramp-up schedules.

\section{RAMP-UP CONCEPTS AND METHODS}

\subsection{Scope}

A key element for the lead time decrease and quick production rate achievement is a good management of the ramp-up stage. It can be considered as the first gate of the 'StageGate' model presented in the eighties to guide the new product introduction [16], the first practical check of the product feasibility.

The criticality of the ramp-up stage is mostly related to the flexibility required. Most engineering changes are made during the ramp-up of new products, motivated by manufacturability issues [17]. After the first iterations of the production process, possible mistakes in the planning or even in the design of the product become apparent and trigger modifications in the production system. Consequently, the more effort is put in the design and planning of the ramp-up, the more efficient it will be in terms of time and cost. 
Reaching the maximum output quickly in turn shortens the time for the investment payback and decreases the opportunity cost due to revenue losses. Many companies are even creating dedicated teams for ramp-up management [8]. They in turn can use rampup strategies and reference models that are available [e.g. 14,18].

To facilitate the progressive increase of production rate, companies should adopt a holistic perspective during the ramp-up process $[11,19]$. The information, should be updated to prevent biased interpretations of the performance achieved and wrong decision-making. It should consider all the aspects of the business to obtain a global and meaningful view of the process. Information about product, manufacturing process, equipment required and impact on costs should be available at the early stages to avoid additional costs and risks as the project proceeds [20].

Therefore, assessing ramp-up should consider:

- the information about process (including learning effects), equipment and costs

- the flexibility needed to simulate likely engineering changes and appreciate the effect on time and costs

\subsection{Learning and forgetting}

The ramp-up period can be seen as a key opportunity for a company to improve its performance. New methods are put in place for the first time and the real production starts up, bringing challenges and initial inertia before achieving acceptable output. Lenfle and Midler [8] consider ramp-up as a 'key learning opportunity', where the management effort should be on facilitating process improvement in the shortest amount of time through its staff. The same authors affirm also that workers' learning is the focal variable to enhance the ramp-up efficiency.

Ramp-up can be defined as a learning process [3]. Pruett and Thomas [12] analyse the impact of learning, traditionally applied to the production process, in product innovation. They include both existing product changes and new product introduction and adopt statistical analyses to develop a correlation model to study the influence of product and innovation variables on company learning. Indeed, the literature agrees that a ramp-up of output rate and learning curve phenomena are strictly correlated. The relationship is so strong that some authors like Pegels [21] tend to overlap the two concepts as differences in learning rate imply differences in ramp-up time.

If the output rate reached at the end of the ramp-up phase is related to learning, it is reasonable to infer that low-volume products have a slower learning than high-volume products. Additionally, the serial output rate to reach is different. Similarities in processes and products support the learning spillage and can limit the uncertainty of the ramp-up [1] and shorten the time-to-volume.

Workers can learn as well as forget. For this reason some authors also consider the effect of forgetting. Authors have developed forgetting models for which characteristics include: experience gained before breaks, duration of breaks and re-learning rates. Where rampup is continuous and staff profiles are stable, forgetting effects can be considered minimal.

\subsection{Learning curves}

A learning curve (LC) is a mathematical description of the improvement in job performance due to the experience acquired through repetition. Alchian [22] expresses the interest of 
the defence industry and U.S. Air Force in LCs, stating that they are applied in planning, scheduling and forecasting. Even if the first applications of LCs concerned labour-intensive operations like aircraft production, capital-intensive operations can present learning phenomena as well [23]. Indeed, all manufacturing companies experience effects of learning [24], hence each kind of industry can take advantage of applying LCs concepts to management. In the literature it is possible to find examples of application of the LCs theory to several industries like electronics $[23,25]$, aircraft $[22,26]$, electricity generation [27] and ceramic tiles [17].

Between the 1930s and 1960s the use of LCs was focused on product manufacturing; later on they were applied to management and organisational issues [27]. Hence, it is possible to distinguish between organisational learning and labour learning [28] which will have different learning rates [29]. The idea of organisational learning is that the whole organisation is subject to learning, not only the single workers. This can be related with the existence of two orders of learning of, first, learning inducted by execution of tasks and, second, learning inducted through managerial or engineering action [23].

\subsection{Capacity}

Learning curves (LCs) can bring huge advantages for a company if employed during early planning. The longer the cycle times the more influential the learning, hence this is especially relevant to engineering products. Consideration of LCs in decisions making (e.g. materials supply and capacity planning) is vital in such environments [30]. The effects of LCs can change also the calculations about variable costs of production [31]. It is quite difficult to find in literature examples of LCs applied to capacity planning during rampup, although this is considered critical by many authors.

Even if production ramp-up and LCs are strongly linked, it is not easy to find examples of practical application of these two concepts. Moreover, the few examples found concern high volume production like semiconductors [10] and assembly [3]. Despite the amount of papers on LC theory and the potential benefits that can derive from more accurate resources plans, there is a lack of literature expressly addressing the forecast of manpower requirements by adopting LC theory [28].

\subsection{Costs}

Many studies show cost modelling [e.g. 32] and the effect of learning [e.g. 12]. Additionally, the literature describes learning in multiple ways, e.g. Kantor and Zangwill [32] use the term 'cost progress curve' as a synonym of LC to stress the cost improvement that can be achieved through learning.

To understand the economic effect of LCs, it is vital to identify which costs are affected by them. It is therefore necessary to clarify first the difference between Recurring Costs (RCs) and Non-Recurring Costs (NRCs). The literature [e.g. 34,35] provides extensive distinction, namely:

- RCs are the repetitive expenditure incurred during the building and testing of every product unit. RCs may be greatly influenced by the effect of LCs [36]. Examples of those costs are basic labour, overtime and rework

- NRCs are all the costs met at the beginning of the product life cycle and not needed for future units within a certain production interval. Expenditure is incurred once and unlikely to occur again in normal conditions. Examples include design, preproduction engineering analyses, jigs, tooling, machinery and infrastructure costs. 
NRCs are fixed for a certain production: they are not directly influenced by the LCs because they represent requirement for the production, so they will increase with the output according to a step shaped function

Although the criteria adopted for the distinction seem straightforward, there is confusion about the way to distinguish between RCs and NRCs [36]. This causes differences from company to company and in some cases from project to project, depending on the business and the internal policy adopted. The absence of broadly accepted definitions leads to a lack of clarity about the topic. Simplistically, the distinction between the two categories of cost can be time, i.e. if the expenditure occurs at the beginning of the life cycle, it is a NRC. If it occurs during the production it is a RC. However, there are RCs and NRCs in all stages. For example, the costs of material and labour of test-units built during the ramp-up phase are considered as RCs while the design and testing costs are NRCs [36]. Additionally, the procurement or relocation of capital equipment may be phased as not all capital equipment needs to be purchased or moved when demand is low at the start of the ramp up period.

There are currently two approaches that reflect two schools of thought [36]:

- Cost estimating approach: the US Department of Defence (DoD) defines RCs as "repetitive elements of development and investment costs that may vary with the quantity being produced during any program phase" and NRCs as "those elements of development and investment costs that generally occur only once in the life cycle of a system". So the investment costs can belong to one category or the other depending on their frequency

- Acquisition approach: the FAR (Federal Acquisition Regulation) defines RCs as "costs that vary with the quantity being produced such as labour and materials" and NRCs as "those costs that are generally incurred on a one-time basis". So everything that is related to testing, research and investment is directly considered as NRC

Further confusion occurs when comparing the RCs and NRCs with the variable and fixed costs.

- Firstly, the field where the two cost categories are used is different. RCs-NRCs classification is used to identify the effect of learning and facilitates the cost estimating process of a project. Variable-fixed cost classification can be used for break-even analyses to identify the investment profitability, so it is adopted in general financial studies

- Secondly, the behaviour with the output is different. The association of NRCs with fixed costs can be accepted since they do not vary with the output within a certain interval. On the other hand, it is inexact to compare RCs with variable costs because the recurring overheads, e.g. energy consumption expenses, are instead fixed [37]

Once the classification of costs has been made, independently of the method followed, the total manufacturing cost will be obtained adding the RCs and NRCs since they encompass all the costs that appear during the product life cycle stages [38]. The Learning Curves (LCs) theory is linked to management control and represents a powerful tool for accurate cost analysis.

As literature explains widely, LCs influence costs during production because of the acquired expertise and diminishing time usage and resource waste [28,32]. The LC 
"provides an empirical relationship between changes in direct manufacturing costs and the volume of production" [39], so that direct costs can be predicted using the LC.

LCs shape RCs in a nonlinear way: the first units produced heavily influence RCs and then $\mathrm{RCs}$ remain constant as the serial or steady state is reached [34]. However, it is important to note an anomaly in NRCs which can occur due to the effects of learning during a very steep ramp-up: If the rate of production ramp-up is faster than the rate of learning (i.e. a steep ramp-up at the start of production when cycles are at their longest due to the effects of learning), then this can drive a short-term requirement for additional production equipment (NRCs) that is greater than the requirement for serial production as suggested in [46]. This additional equipment will not be needed once production has ramped up to the target serial rate, and learning has been achieved. Due to this anomaly, it is often preferable to smooth the rate of ramp-up to within the boundaries of NRCs as set by target serial production.

\section{RAMP-UP MODELLING}

Available literature contains few examples of ramp-up modelling; most of the production modelling literature focuses on steady state of the system [40,41]. Of the modelling work that is available little explicitly links ramp-up with capacity acquisition, learning curves and costs simultaneously.

Terwiesch and Bohn [4] illustrate an analytical method to describe the ramp-up considering the capacity as a constraint. The main objective is to optimise the yieldsoutput ratio given a certain level of capacity. Another mathematical model used is the Stream of Variation (SoV) methodology: it does not directly model the ramp-up but it is used to identify the root causes of manufacturing errors during the ramp-up and production time. It traces the propagation of variation along the different processes. The main objective is the elimination of costly trial-and-error and get the product right the first time. The main effect is the reduction of the ramp-up duration [9,42,43]. Winkler et al. [44] develop a conceptual model with supporting prognosis tools for the management of rampup projects.

Fleischer et al [45] present detailed ramp-up simulations for the automotive industry for varying levels of ramp-up maturity using capability curves. This work in turn has been extended to supply chains and value networks [46]. The work implies volume rather than more complex, lower volume engineered product. Additionally, cost is referred to in this work but it does not feature highly. The literature presents several case studies to illustrate cost models built by companies:

- Mejean and Hope [47] and Kellogg and Phan [48] illustrate models created to study the correlation between the parameters identified and the total cost

- Rosenberg et al. [49] illustrate a parametric cost model for estimating the costs of future space missions

- Roy et al. [50] show the Airframe Cost Model that adopts the distinction of RCs and NRCs to give product estimations

- Rehman [51] develops a prototype for modelling production costs using the knowledge-based and case-based approaches

The literature contains many references to volume ramp-up, strategies for ramp-up and support systems for the control of the ramp-up. The models presented in literature mostly analyse the different methodologies to estimate the product cost and study its sensitivity to 
specific factors. They do not address the estimation of ramp-up costs considering learning curve effects directly.

Despite the work from the above authors, the area of ramp-up modelling is immature and poorly documented with a lack of general approaches and techniques and poor practical examples. To place in context, this work aligns to the early stages of the configuration stage of reference model proposed by Hüntelmann et al. [14].

\section{DEVELOPMENT AND IMPLEMENTATION OF MODEL ARCHITECTURE}

To address the short comings evident from the literature a concept for a ramp-up model was created. This in turn defines the prototype ramp-up simulation tool used in the case company.

The output requirements for understanding ramp-up are as follows (both final as well as during ramp-up):

1. Equipment required and production output (inc. utilisation)

2. Space requirements (including size and number of production equipment as well as storage)

3. Recurring Costs (RCs)

4. Non-Recurring Costs (NRCs)

For each of these outputs, inter-related calculations need to be carried out, broadly in the sequence specified. In order to carry out these calculations the following inputs are required:

1. Equipment required and utilisation: Capacity and reliability of individual machine tools; production plan; routings, operation cycle times.

2. Space requirements: Footprint of individual machine tools; number of machines; space restrictions.

3. RCs: Staff; staff categories; shifts; pay rates; shift rates; learning curves; maintenance; utilities; consumables; production rates, man hours, Standard Time Values (STV).

4. NRCs: Machine tool requirements and costs; space required; space costs; cycle times

In turn to calculate some of these inputs additional data is required:

5. Production plan: Demand; product structure.

6. Learning curves: Learning rates; number of learning phases

Essentially, therefore there are six major categories of calculations for a broad understanding of production ramp-up that are interlinked. Examination of the RCs showed that the staff related RCs were largely independent of the production RCs and hence they can be split. Modules can be created to support the now seven major categories of calculations. Taking the inputs and outputs from above, the interrelationships between these modules are shown in Figure 2. The diagram shows the link between capacity, learning and cost driven by the ramp-up production plan. The maximum production rate, utilisation and configuration outputs must be generated through optimisation whilst all other outputs can be generated through single stage calculations. 


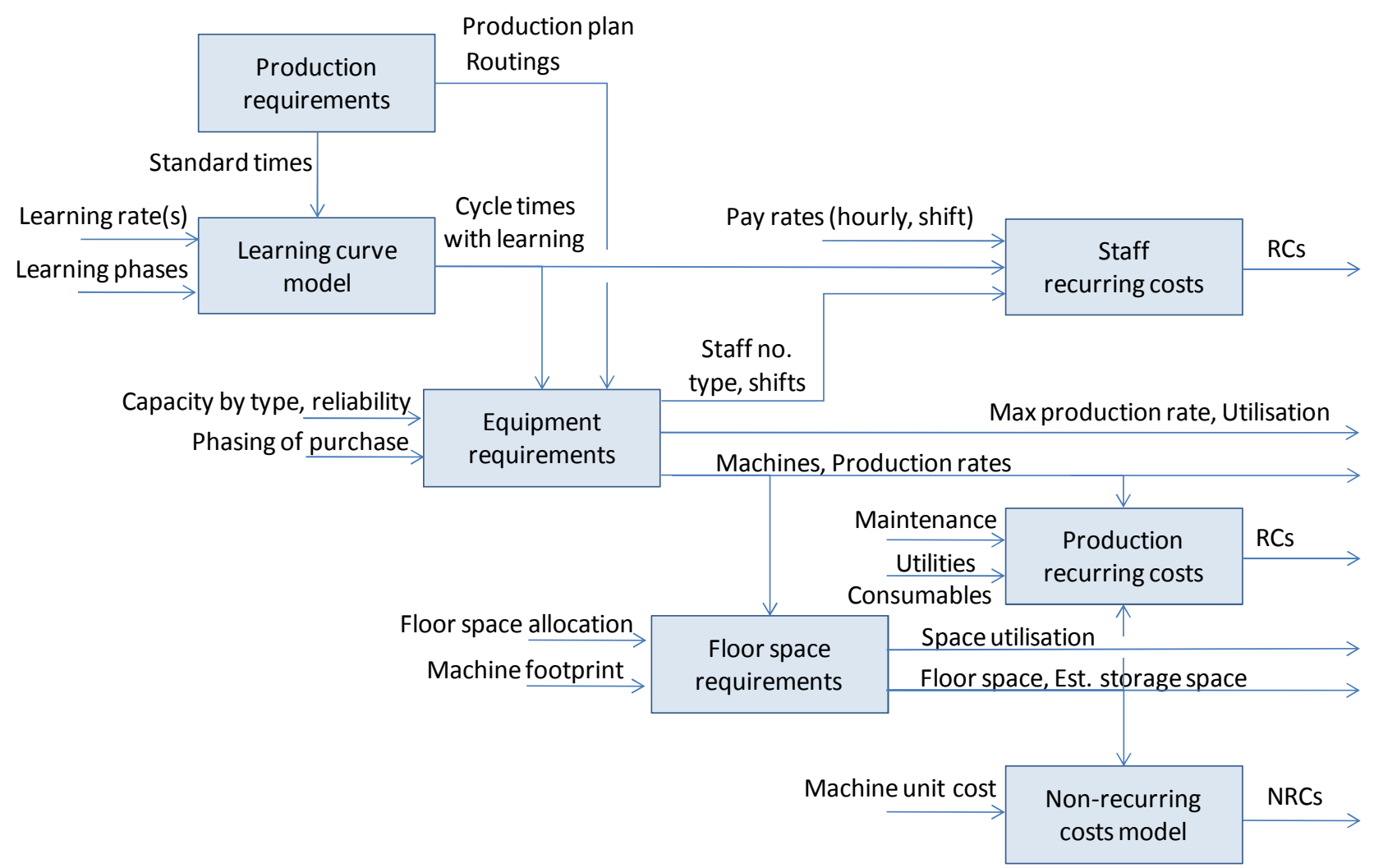

Figure 2. Conceptual design of a ramp-up modeller showing modules with associated inputs and outputs

Regardless of how this design is implemented, it is important to maintain flexibility in any tool to be able to cope with different ramp-up strategies and to be reused during ramp-up to model any changes to the chosen ramp-up strategy.

In order to implement this conceptual design into a tool for understanding the behaviour of ramp-up a choice of software implementation has to be made. Modelling tools can range from bespoke configuration of spreadsheets through to the utilisation of dynamic modelling environments such as discrete event simulation (DES) software. Spreadsheets (e.g. Excel [52]) have the advantage of being readily available and easy to use [53] as well as being able to visually hold and manipulate significant amount of data. At the other end of the spectrum DES software (e.g. Arena, Simul8 or Witness) are able to model the passage of time, are preconfigured with manufacturing constructs with typical parameter types and present dynamic output numerically as well as graphically. Most tools can represent costs to varying degrees of depth and flexibility.

For this work, spreadsheets (Microsoft Excel) are an appropriate means for the first implementation of the conceptual design for several reasons. Firstly, spreadsheets have considerable flexibility and therefore able to cope with this prototype application development. Secondly, spreadsheets can be configured to represent the passage of time in broad time intervals for which simulation software could be overly complex. The problem domain here is of a type that is non-steady state and time based for which spreadsheets would not be an obvious choice. However, for the application area of the engineering products the learning curves span months or more and granularity of time progression is less important than for shorter duration, more repetitive ramp up applications. Thirdly, the development of random variation could be incorporated into spreadsheets if appropriate. The learning from this application could inform later more detailed simulation model development. 
A number of assumptions in this design and its implementation should be noted. The effect of inflation was ignored. The model focused on a single product type ramp-up and assumed no effects from other ramp-ups or other company activities. Stochastic behaviour was ignored. Although random variables could be incorporated into Excel or other tools initially or subsequent to development, it was judged that significant behaviour could be observed running in deterministic mode alone. Additionally, sensitivity analysis was used in the verification as well as experimentation stages which lessened the need for random variable inclusion. Finally, learning curves are 'back-to-back' and so the forgetting factor between phases of learning is ignored. If it was to be considered, forgetting could be explicitly defined or incorporated in the learning curve for the next phase. In part, this is related to the assumption of ramping up a single new product and therefore there is no movement of staff.

For modelling ramp-up in the breadth described earlier there is little prior work to build on. Therefore the focus of the work is on a prototype rather than refining earlier tools. Additionally the work is directed particularly to engineering products that have longer leadtimes than higher volume products hence fidelity in the modelling of time was not significant. Finally, costing requires significant analysis and hence flexibility here is highly desirable. For these reasons spreadsheets were considered the most appropriate platform on which to build the prototype ramp-up modelling tool. The modules identified above could be implemented across multiple worksheets and workbooks and the flow of information and types of calculations were more important rather than physical implementation detail.

The development of the modelling tool followed the 'waterfall model' of following steps: concept, system requirements, architectural design, detailed design, code \& test, integration, deployment [52]. The concept, system requirements and architectural design are documented above. Coding and subsequent integration was carried out using standard functionality and bespoke macros wholly within Microsoft Excel. Verification was planned and executed rigorously at module and overall tool level. This identified a number of errors that were removed and the tests repeated. The tests included: syntax analysis, semantic analysis, traceability assessment, traces, face validation and sensitivity analysis (e.g. [54]) and amounted to many thousands of individual checks. The modelling tool was then repopulated with case company data and experiments performed to inform the design and policy setting for a forthcoming significant production ramp-up.

A screen shot of the modelling tool is shown in Figure 3. This particular screen shot shows the production variable and man-hour calculations. It illustrates a particular feature of the prototype that enables multiple learning curves to be incorporated to capture the behaviour resulting from multiple waves of capital equipment purchases, release of engineering changes or product model evolution. Note: data has been modified and parts of the screen shot have been removed to avoid implying the identity of any particular company or the case company.

In the upper part of the spreadsheet the user inputs allow the identification of each of the learning curves (ranges) in order to model the operators' improvement change over time. This important feature can also be used to simulate possible modifications of the production process that result in different man-power learning rates. To get the four branches of hyperbola, the user is asked to input the length of the range in terms of product number, the improvement rate and the site parameters. There are two site parameters: STV, which is the theoretical number of man-hours per product, and learning 
factor (LF), which is the correction factor to take into account the actual production conditions and represents in fact the ratio between the actual man-hours and the planned STV (LF is always $>1$ so that it increases the number of hours virtually needed). From this data, calculations are carried out in the lower part of the spreadsheet to obtain the amount of man-hours necessary to complete the product considered. A learning factor is calculated from the improvement rate and gives the opportunity to find the man-hour factor (time reduction in the range due to the learning phenomenon). Eventually the total manhours per product are derived once the theoretical value (pure L/C) has been corrected with the LF.

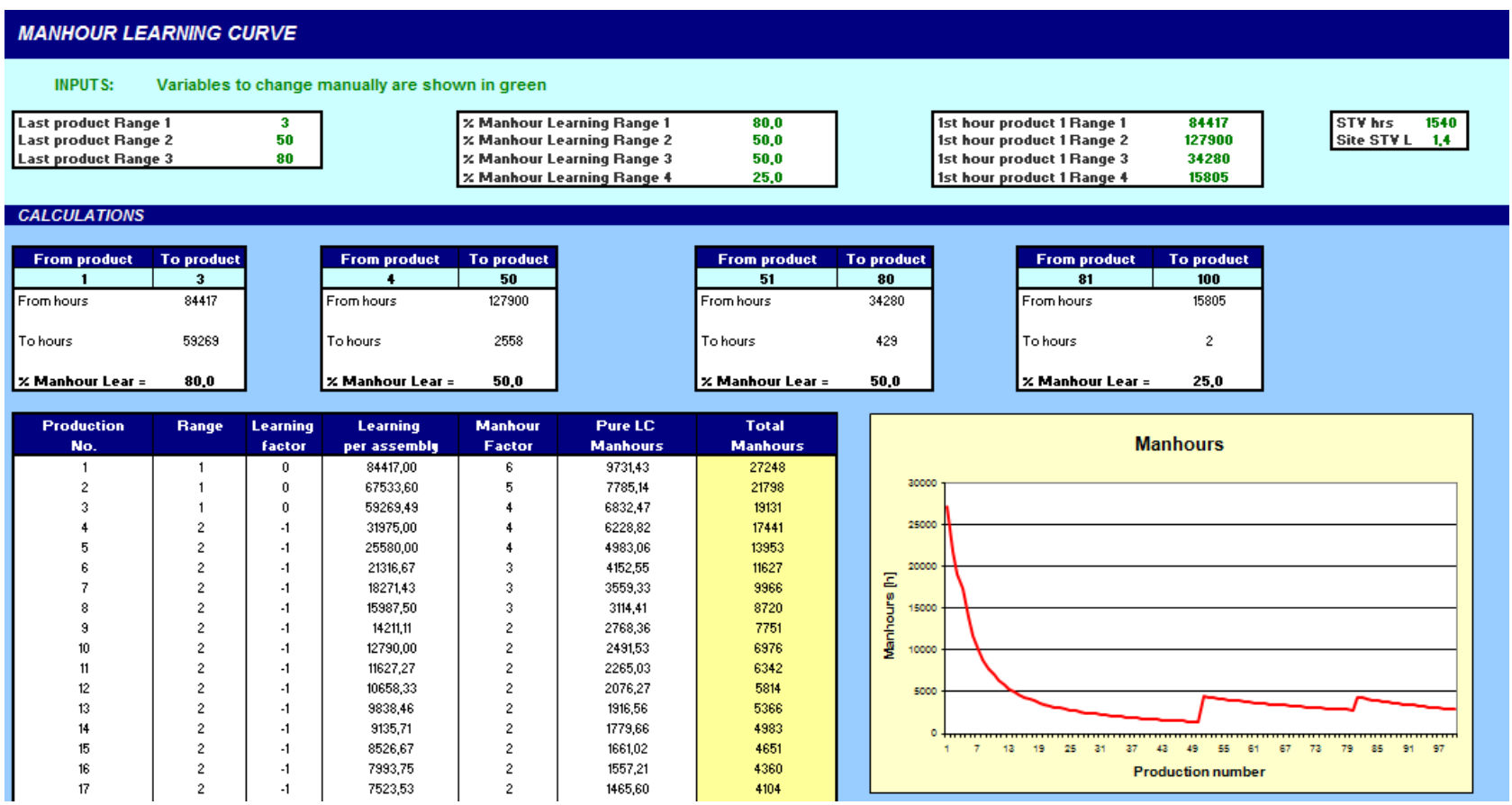

Figure 3. An illustration of the ramp-up modelling tool inputs

Figure 4 shows typical graphs created by the modelling prototype. Again the waves seen in the graphs are a result of incorporating multiple learning curves to capture particular behavioural traits of the case company. The cost results displayed derive from calculations built up from the RC and NRC modules.
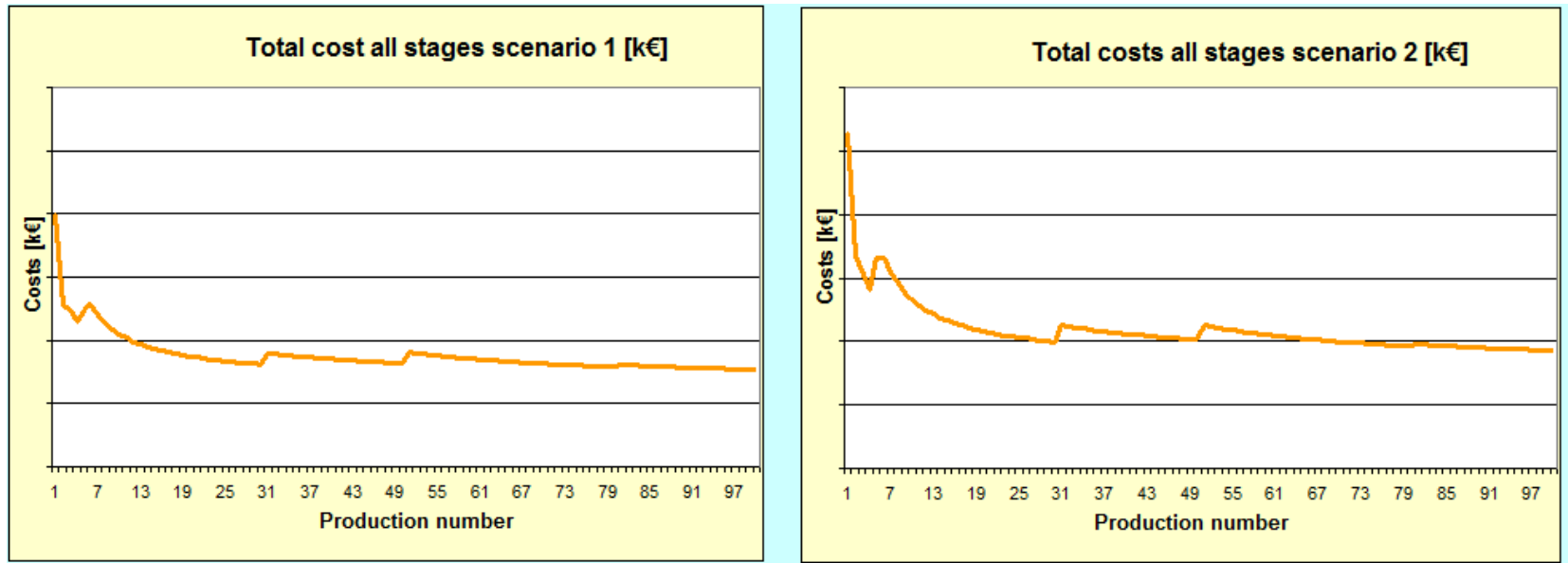

Figure 4. An illustration of the ramp-up modelling tool outputs 
Using the modelling tool, the production ramp-up plans of an engineering product were evaluated. The model was built using typically available data. The cost calculations were adapted to the particular company requirements. Whilst the technically possible standard times could be calculated from previous product equipment data, deriving learning rates was more challenging and these were estimated using historical data as a benchmark. The potentially significant errors arising from choice of learning rates were addressed through sensitivity analysis.

\section{RESULTS}

Experiments were conducted on product features, learning rates, production technology, cycle times, equipment phasing and work allocation. Examples of the experiments carried out for the case company are illustrated below and general observations from all experiments are then made. Values are presented as percentage and not in absolute value for confidentiality reasons.

The ramp-up model can be used to assess the impact of variable changes on the aggregate ramp-up performance. For instance, what does a change in the percentage of work allocated to three different machines at a given operation stage doing the same job, imply on floor space requirements and for the total costs of ramp-up (see Table 1 and Table 2). The work allocation percentage is not based on utilisation of each machine but on the capabilities of individual machines to contribute to the overall work, so smaller machines with a varying footprint and output are traded against cost. The impacts are significant and will have a significant impact on costs.

Another test was performed changing the value of the cycle time at the steady stage in one of the production stages (Table 3). The change in the steady state cycle time value also influences ramp-up due to the effects on the learning rate. The effect of this variable on the overall cost of ramp-up and on the total cost of ramp-up per year is captured, with the impact of the change more noticeable in years characterised by a high production rate.

Table 1 - Percentage variation of floor space requirements due to work allocation

\begin{tabular}{c|c|c|c|c} 
Work allocation to & \multicolumn{4}{|c}{ Variation of floor space requirements (\%) } \\
\cline { 2 - 5 } machines $\mathbf{x}, \mathbf{y}, \mathbf{z}(\%)$ & year 1 & year 2 & year 3 & year 4 \\
\hline $30-30-40^{*}$ & 0 & 0 & 0 & 0 \\
$10-30-60$ & -28.7 & 0 & -26.7 & -23.1 \\
$12-12-76$ & -57.4 & 0 & -6.9 & -46.3 \\
$25-25-50$ & 0 & 0 & 0 & 0 \\
$40-40-20$ & -42.6 & 0 & +26.7 & +19.4 \\
& & & & * base case
\end{tabular}

Table 2 - Percentage variation of ramp-up costs due to work allocation

\begin{tabular}{c|c|c|c|c|c} 
Work allocation to & \multicolumn{6}{|c}{ Variation of costs (\%) } \\
\cline { 2 - 6 } machines $\mathbf{x}, \mathbf{y}, \mathbf{z}(\%)$ & year 1 & year 2 & year 3 & year 4 & total \\
\hline $30-30-40^{*}$ & 0 & 0 & 0 & 0 & 0 \\
$10-30-60$ & -1.4 & 0 & -4.9 & -7.0 & -2.9 \\
$12-12-76$ & -2.4 & 0 & -2.8 & -11.4 & -3.6 \\
$25-25-50$ & 0 & 0 & 0 & 0 & 0 \\
$40-40-20$ & -0.7 & 0 & +4.0 & +6.5 & +1.9
\end{tabular}


Table 3 - Percentage variation of ramp-up costs due to steady state cycle time variation

\begin{tabular}{c|c|c|c|c|c} 
Steady state cycle & \multicolumn{5}{|c}{ Variation of costs (\%) } \\
\cline { 2 - 6 } $\begin{array}{c}\text { time in operation } \mathbf{x x} \\
\text { (\% to base case) }\end{array}$ & year 1 & year 2 & year 3 & year 4 & total \\
\hline $100^{*}$ & 0 & 0 & 0 & 0 & 0 \\
60 & 0 & -1.3 & -7.9 & -11.6 & -4.9 \\
80 & 0 & -1.3 & -4.8 & -5.1 & -2.6 \\
120 & 0 & 0 & +3.2 & +5.1 & +2.0 \\
140 & 0 & +1.3 & +7.9 & +11.6 & +4.9
\end{tabular}

The tests performed showed that the modelling tool can be used to assess different rampup scenarios in order to choose the one that best fits the organisation's objectives. These results focus on particular areas of experimentation. Other experimentation was carried out and general, observations were made. The observations that follow are in general obvious but the impact of them requires the modelling tool to evaluate.

The major learning benefit occurs early in the production ramp-up and the staff skill level required has a major impact on recurring costs. Hence to minimise recurring cost (RC) particular attention should be paid to simplifying operator tasks and initial training.

By increasing the rate of learning, the ramp-up will be faster and RCs lower. To counteract the learning effects and achieve a higher ramp-up rate than possible with the rate of learning then higher Non-Recurring Costs (NRCs) must be incurred earlier. This could result in short-term requirement for additional production equipment (NRC) than is required for later, steady-state production. Due to this anomaly, it is typical to smooth the rate of ramp-up to within the boundaries of NRCs as set by target serial production.

Relationships between the variables covered in this paper are difficult to generalise as they are specific to the case in question that is heavily influenced by the product features, production volumes, ramp rates, labour costs, etc. Hence, application of sensitivity analysis for particular cases is important to understand the general behaviour and particular risk areas in the production ramp-up planning.

\section{DISCUSSION}

The development of the production ramp-up modelling prototype has drawn extensively from different areas of available literature. The work addresses a knowledge gap through the integration of these areas - capacity, learning curves and costs for ramp-up. The modules created in the modelling tool align to these particular areas of focus. Through the use of standard modelling techniques and verification, experimentation can then be performed for a particular company data set.

The strength of the modelling tool lies in its ability to evaluate the robustness of particular ramp-up scenarios and explain subsequent adherence to financial planning. The modelling tool explicitly demonstrates that poor financial adherence tends to result from changes in Recurring Costs (RCs) due to changes in the production system (e.g. introduction of modifications) and the subsequent difficulties in recovering the backlog that ensues. In turn, the tool demonstrates that this directly impacts ramp-up capability. 
The values of cost and other metrics for particular ramp-up approaches can be assessed both in absolute terms as well as for sensitivity to variation of particular inputs. In assessing this, the importance of the distinction between RCs and NRCs as discussed earlier is clear. For example, an RC cost will be impacted by the position on the Learning Curve, whereas an NRC will not.

The ramp-up prototype was developed to calculate output and costs according to learning and production inputs. Multiple learning phases can be modelled to show the impact of major changes in production. For instance, product design modifications will drive alternate ramp-up capabilities depending on whether they are introduced individually or in batches. Optimisation has been built into the tool to back calculate the ramp-up rates according to the phasing of available space and equipment. The common theme here is working with multiple constraints in an integrated way.

\section{CONCLUDING REMARKS}

The body of knowledge in the area of production ramp-up is limited and typically focuses on narrow aspects of the field of learning curves, capacity or costs. Additionally, there is an absence of tools and methodologies specifically addressing ramp-up.

This paper has explored the literature and identified the key components of an architecture for modelling production ramp-up of engineering products. The objective was addressed through the development of a spreadsheet based prototype described.

The work has shown how the different aspects of production ramp-up can be considered together in a single integrated tool. In turn this could provide greater understanding of a particular product ramp-up strategy leading to lower time and cost in decision making. In particular it has shown the ability to consider capacity, complex learning curves and broad cost analysis simultaneously in ramp-up. Thereby, this work has provided an insight into a link between the forecasting of labour requirements and learning curve theory that is lacking in the literature.

It is the interaction of the breadth of factors that influence ramp-up design and performance that make this such a challenging area to address. The prototype modelling tool presented in this paper was developed from an understanding of the relationships between the influencing factors rather than treating them independently. The result is greater insight into ramp-up performance whilst respecting key constraints that exist in capacity, learning and costs.

[Revision increased 5500 words to 6550 words excluding tables and references]

\section{REFERENCES}

1 Haller, M., Peikert, A. and Thoma, J. Cycle time management during production ramp-up, Robotics and Computer-Integrated Manufacturing, 2003, 19(1-2), 183-188.

2 Terwiesch, C., Bohn, R. E. and Chea, K. S. International product transfer and production ramp-up: A case study from the data storage industry, $R$ and $D$ Management, 2001, 31(4), 435-451.

3 Casamento, J. W. A model for predicting and managing a production ramp-up of a new product (unpublished MSc in Management and MSc in Mechanical Engineering thesis), Massachusetts Institute of Technology, 1992.

4 Terwiesch, C. and Bohn, R.E. Learning and Process Improvement during Production Ramp-Up, International Journal of Production Economics, 2001, 70(1), 1-19. 
5 Almgren, H. Pilot production and manufacturing start-up: The case of Volvo S80, International Journal of Production Research, 2000, 38(17), 4577-4588.

6 Clawson, R. T. Controlling the manufacturing start-up, Harvard Business Review, 1985, 63(3), 6-20.

7 Abernathy, W. J. and Baloff, N. A methodology for planning new product start-ups, Decision Science, 1973, 4(1), 1-20.

8 Lenfle, S. and Midler, C. The launch of innovative product-related services: Lessons from automotive telematics, Research Policy, 2009, 38(1), 156-169.

9 Du, S., Xi, L., Ni, J., Ershun, P. and Liu, C. R. Product lifecycle-oriented quality and productivity improvement based on stream of variation methodology, Computers in Industry, 2008, 59(2-3), 180-192.

10 Sturm, R., Dorner, J., Reddig, K. and Seidelmann, J. Simulation-based evaluation of the ramp-up behavior of waferfabs, Advanced Semiconductor Manufacturing Conference and Workshop, 2003 IEEEI/SEMI, 31/03-01/04, 111-117.

11 Fjallström, S, Safsten, K., Harlin, U. and Stahre, J. Information enabling production ramp-up, Journal of Manufacturing Technology Management, 2009, 20(2), 178-196.

12 Pruett, M. and Thomas, H. Experience-based learning in innovation and production, R\&D Management, 2008, 38(2), 141-153.

13 Agaga, T., Brzusczak, V., Oduneye, N., Broxup, B. and Palomino Fernandez, D. Ramp-up (MSc Group Project Report), Cranfield University, Cranfield, 2008.

14 Hüntelmann, J., Reinsch, S. and Märtens, A. Logistic- and cost-oriented cross-company ramp-up planning, in Digital Enterprise Technology Perspectives and Future Challenges, Eds Cunha, P.F. and Maropoulos, P.G., Springer, 2007, 115-122.

15 Meredith, J. Theory building through conceptual methods, International Journal of Operations and Production Management, 1993, 13(5), 3-11.

16 Cooper, R. G. How companies are reinventing their idea-to-launch methodologies, Research Technology Management, 2009, 52(2), 47-57.

17 Chatzimichali, A. P. and Tourassis, V. D. Towards a Learning Curve Theory for Batch Production, Democritus University of Thrace, Xanthi, Greece, 2008.

18 Schuh, G., Desoi, J.-C., and Tücks, G. Holistic approach for production ramp-up in automotive industry, in Advances in Integrated Design and Manufacturing in Mechanical Engineering, Eds Bramley, A., Brissaud, D. and McMahon, C., Springer, 2005, 255-268.

19 Koss, J. P. Production line start up, Beverage World, 1996, 115(1627), 84-85.

20 Mountney, S. L., Gao, J. X. and Wiseall, S. A knowledge system to support manufacturing knowledge during preliminary design, International Journal of Production Research, 2007, 45(7), 1521-1537.

21 Pegels, C. C. Start Up or Learning Curves - Some new approaches, Decision Science, 1976, 7(4), 705713.

22 Alchian, A. A. Reliability of Progress Curves in Airframe Production, RM-260-1, The RAND Corporation, Santa Monica, CA. 1950.

23 Adler, P. S. and Clark, K. B. Behind the Learning Curve: a Sketch of the Learning Process, Management Science, 1991, 37(3), 267-281.

24 Womer, N. K. Estimating Learning Curves from Aggregate Monthly Data, Management Science, 1984, 30(8), 982-992.

25 Balasubramaniam, S., Sarwar, A. K. and Walker, D. M. H. Yield Learning in Integrated Circuit Package Assembly, Components, Packaging and Manufacturing Technology, 1997, 20(2), 133-141.

26 Benkard, C. L. Learning And Forgetting: The Dynamics Of Aircraft Production, American Economic Review, 2000, 90(4), 1034-1054.

27 Jamasb, T. Technical Change Theory and Learning Curves: Patterns of Progress in Electricity Generation Technologies, The Energy Journal, 2007, 28(3), 51-71.

28 Yelle, L. E. The learning curve: historical review and comprehensive study, Decision Sciences, 1979, 10(2), 302-328.

29 Argote, L. and Epple, D. (1990), Learning curves in manufacturing, Science, 1990, 247(4945), 920-924.

30 Liao, W. M. Effects of Learning on Resource Allocation Decisions, Decision Science, 1979, 10(1), 116125.

31 Biskup, D. A state-of-the-art review on scheduling with learning effects, European Journal of Operational Research, 2008, 188(2), 315-329.

32 Wang, Q. and Stockton, D. J. Cost model development using artificial neural networks, Aircraft Engineering and Aerospace Technology, 2001, 73(6), 536-541.

33 Kantor, P. B. and Zangwill, W. I. Theoretical foundation for a learning rate budget, Management Science, 1991, 37(3), 315-330.

34 Chen, G. and McLennan, D. D. A study of learning curve impact on three identical small spacecraft, Proceedings of 2004 IEEE Aerospace Conference, 6, 3970-3976. 
35 Curran, R., Kundu, A., Raghunathan, S., Eakin, D. and McFadden, R. Influence of manufacturing tolerance on aircraft direct operating cost (DOC), Journal of Materials Processing Technology, 2003, 138(1-3), 208-213.

36 Myers, J. The importance of Recurring and Nonrecurring costs, Contract Management, 2007, 3, 36-39.

37 Curran, R., Raghunathan, S. and Price, M. Review of aerospace engineering cost modelling: The genetic causal approach, Progress in Aerospace Sciences, 2004, 40(8), 487-534.

38 Butterfield, J., Curran, R., Watson, G., Craig, C., Raghunathan, S., Collins, R., Edgar, T., Higgins, C., Burke, R., Kelly, P. and Gibson, C. Use of Digital Manufacturing to Improve Operator Learning in Aerospace Assembly, 7th AIAA Aviation Technology, Integration and Operations Conference (ATIO) 2nd C, vol. 7865, 18 - 20 September 2007, Belfast, Northern Ireland, AIAA.

39 Hax, A. C. and Majluf, N. S. Competitive Cost Dynamics: The Experience Curve, Interfaces, 1982, 12(5), 50-61.

40 Sharma, K.R., Yuan, Z., de Haas, D., Hamilton, G., Corrie, S. and Keller, J. Dynamics and dynamic modelling of H2S production in sewer systems, Water Research, 2008, 42(10-11), 2527-2538.

41 Baykoç, O. F. and Erol, S. Simulation modelling and analysis of a JIT production system, International Journal of Production Economics, 1998, 55(2), 203-212.

42 Ceglarek, D., Huang, W., Zhou, S., Ding, Y., Kumar, R. and Zhou, Y. Time-Based Competition in Multistage Manufacturing: Stream-of-Variation Analysis (SOVA), International Journal of Flexible Manufacturing Systems, 2004, 16(1), 11-44.

43 Barhak, J., Djurdjanovic, D., Spicer, P. and Katz, R. Integration of reconfigurable inspection with stream of variations methodology, International Journal of Machine Tools and Manufacture, 2005, 45(45), 407-419.

44 Winkler, H., Heins, M. and Nyhuis, P. A controlling system based on cause-effect relationships for the ramp-up of production systems, Production Engineering Research Development, 2007, 1, 103-111.

45 Fleischer, J., Lanza, G. and Ender, T. A Dynamic Business-Process Based Production Ramp-up Simulation Model, Production Engineering, 2006, 13(2), 197-200.

46 Lanza, G. and Ude, J. A concept for the configuration of value added networks based on quality capabilities ramp-up, in Digital Enterprise Technology Perspectives and Future Challenges, Eds Cunha, P.F. and Maropoulos, P.G., Springer, 2007, 393-400.

47 Mejean, A. and Hope, C. Modelling the costs of non-conventional oil: A case study of Canadian bitumen, Energy Policy, 2008, 36(11), 4205-4216.

48 Kellogg, R. and Phan, S. An analogy-based method for estimating the costs of space-based instruments, Proceedings Aerospace Conference, IEEE, 2003, 8, 3843-3847.

49 Rosenberg, L., Hihn, L., Roust, K. and Warfield, K. Parametric Cost Modeling of Space Missions Using the Develop New Projects (DNP) Implementation Process, INCOSE Symposium, 1999, Brighton, UK.

50 Roy, R., Kelvesjo, S., Forsberg, S. and Rush, C. Quantitative and qualitative cost estimating for engineering design, Journal of Engineering Design, 2001, 12(2), 147-162.

51 Rehman, S. Knowledge-based cost modelling for innovative design, PhD Thesis, 2000, Cranfield University, Cranfield

52 NASA Cost Estimating Handbook, NASA HQ, 2002, Washington DC.

53 Hogan, M. Development of an Integrated Cost Model for Single Living Acquisition, MSc Thesis, 2005, Cranfield University, Cranfield.

54 Balci, O. Verification, Validation, and Testing, in Banks, J. (ed.) Handbook of Simulation-Principles, Methodology, Advances, Applications, and Practice, John Wiley \& Sons, Inc., USA, 1998, 335-393. 